\title{
GC Determination of Volatile Components in Human Exhalation and in Ambient Atmosphere, after Preconcentration on Solid Sorbents
}

\author{
T. Qin ${ }^{1}$ X. B. Xu ${ }^{1 *} /$ V. Pacakova ${ }^{2} /$ K. Stulik ${ }^{2}$ \\ ${ }^{1}$ Researeh Center for Eco-Environmental Sciences, Beijing 100085, China \\ ${ }^{2}$ Charles University, Albertov 2030, 12840 Prague 2, Czech Republic
}

\section{Key Words}

Gas chromatography

Trace volatile components

Human breath

\begin{abstract}
Summary
A modified GC sampling system and its analytical use are described for the determination of volatile components of human breath or in ambient atmosphere with flame-ionization detection (FID). The difficulties of collection for low concentration samples were alleviated by using a very small trapping column packed with activated charcoal. The collected samples can be measured directly after thermal desorption onto the chromatographic column (packed with Porapak Q). The preconcentration recoveries for pentane, methanol, ethanol and acetone have been studied.
\end{abstract}

\section{Introduction}

Gas chromatography (GC) is generally used to analyze trace volatile organic mixtures in ambient air pollutants, and in clinical investigations to characterize some chemical compounds which indicate or predict certain diseases and malfunctions of the human body [1-6]. Preconcentration methods based on an enrichment step employing a solid adsorbent and thermal desorption have been propose for such applications [7-9].

A simple, reliable and sensitive method for the determination of volatile compounds both in air and in human breath is described in this paper. It is based upon the technique in which the components are first trapped in an adsorption tube, and then, after thermal desorption, separated on a GC column packed with Porapak Q. The needle-like adsorption tube was filled with activated charcoal. This method suggests a simple approach to determine low molecular weight organic components in human breath or in ambient air.

\section{Experimental}

\section{Apparatus and Procedure}

The instrumentation is similar to that used previously for the automatic determination of selected $\mathrm{C}_{2}-\mathrm{C}_{5}$ hydrocarbons in urban air [10]. It consists of a gas chromatograph equipped with dual injectors, two flow controllers, and an FID (we used the CHROM 4 instrument, made in the Czech Republic). To the basic instrument one additional injector port $(G)$ and a flow controller $\left(\mathrm{P}_{3}\right)$ was added; a six-port valve $(\mathrm{B})$ and three three-port valves $\left(E_{1}-E_{3}\right)$ direct the carrier gas (nitrogen) flow to the proper places. Short stainless-steel tubing served to connect the individual components of the system.

Three positions are possible in the system:

(a) For the pre-treatment (cleaning) of the adsorbent tube $\left(T_{1}\right)$, it is connected at valve $E_{3}$, in the position as indicated. In this case the carrier gas flow is controlled by $\mathrm{P} 1$ and is heated by passing through port $A_{1}$; the chromatographic column is bypassed by the proper positioning of valves $B, E_{1}, E_{2}$ and $E_{3}$. In this way the tube is purged and any contaminant present in it will be removed.

(b) If standards are to be analyzed, the adsorbent tube ( $T_{2}$ is inserted into injector $A_{2}$ which is at room temperature, and the standards are injected at $G$. In this case the carrier gas flow is controlled by $P_{3}$, and valves $E_{2}$ and $E_{3}$ are positioned in such way that ni- 


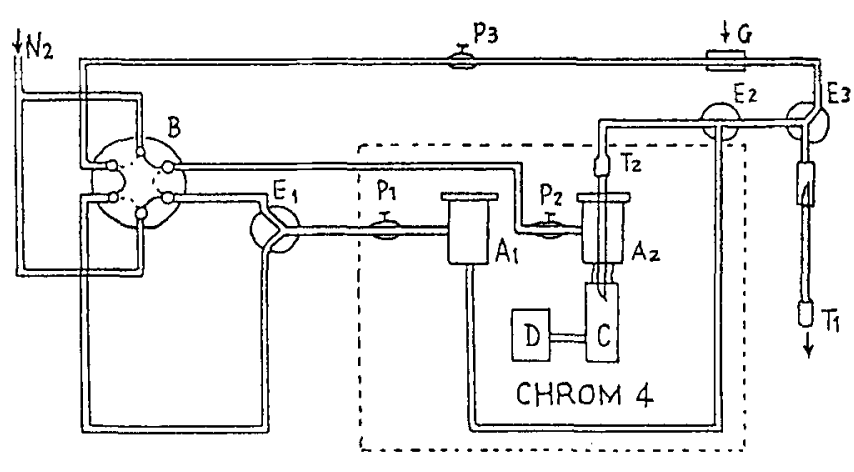

Figure 1

Schematic of the system used for sampling and analysis. $\mathbf{A}_{1}-\mathbf{A}_{\mathbf{2}}=$ $\mathrm{GC}$ injection ports; $\mathbf{B}=$ six-port valve; $\mathbf{C}=$ chromatographic column; $\mathbf{D}=$ flame-ionization detector $; \mathbf{E}_{\mathbf{1}}-\mathbf{E}_{\mathbf{3}}=$ three-port valves; $\mathbf{P}_{1}-\mathbf{P}_{3}=$ carrier gas flow controllers; $\mathbf{G}=$ injection port for the standard; $\mathbf{T}_{\mathbf{1}}-\mathbf{T}_{\mathbf{2}}=$ preconcentration tube: large needle packed with adsorbent.

trogen carries the injected standards into $T_{2}$, while by the proper positioning of the six-port valve $B$, the regular carrier gas flow is maintained to the chromatographic system. Consequently the trapped analytes are desorbed by rapidly heating up injector $\mathrm{A}_{2}$.

(c) If samples were collected at outside locations (using the system shown in Figure 1), the tube with the collected sample is placed into injector $A_{2}$ and desorbed as above, in (b).

\section{Sampling}

The sampling system was designed to enrich the samples collected from either air or breath as shown in Figure 2 the preconcentration tube was actually a free hollow needle from a large syringe, with a small hole at the sharp-edged end. The tube was packed with adsorbent (approx. $0.05 \mathrm{~g}$ ), and glass wool plug was used to secure the filling. The preconcentration system consisted of a portable pump, a flow-rate controller, a big gas-tight syringe, and a breath collector made up of a glass tube and gas container. The large gas-tight syringe could be used to record the volume of the gas sampled through the preconcentration tube.

A controlled volume (200-600 mL) of breath or air sample was directly drawn through the adsorbent needle at room temperature for 10-30 min by a portable pump, with a flow rate of $20-50 \mathrm{~mL} \mathrm{~min}^{-1}$. The collected sample is desorbed into the GC column as shown in Figure 1 and described above, by placing the needle tube in injector $\mathbf{A}_{2}$. The GC analysis should be performed as soon as possible after collection. After use, the sampling needle should be sealed by a silicone rubber piece.

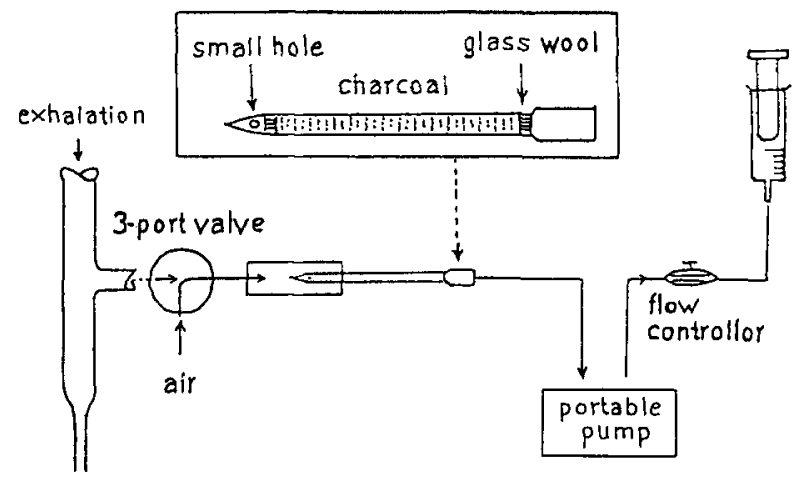

Figure 2

The collecting system for air and breath samples.

\section{Determination and Chromatographic Conditions}

Chromatographic separation was carried out on a stainless-steel packed column $(120 \mathrm{~cm} \times 3 \mathrm{~mm}$ i.d. $)$ containing Porapak Q (80-100 mesh), at $145^{\circ} \mathrm{C}$.

Sample desorption (standards or real samples) from the adsorbent was carried out by inserting the needle tube into injection port $\mathrm{A}_{2}$ at $250^{\circ} \mathrm{C}$. Immediately after insertion, the 6-port valve was switched to the proper position (Figure 1) to introduce the compounds onto the GC column, with the carrier gas at $25 \mathrm{~mL} \mathrm{~min}{ }^{-1}$. The temperature of the FID was $160^{\circ} \mathrm{C}$ and the flow-rates of hydrogen and air were 25 and $300 \mathrm{~mL} \mathrm{~min}^{-1}$, respectively. The concentrations of some typical volatile compounds (methanol, ethanol, acetone and pentane) were quantitatively determined from their respective peak heights. Identification of the individual peaks was carried out using their retention times (Table I).

\section{Results and Discussion}

\section{Adsorbent Selection}

Three different types of solid adsorbents were investigated, namely: Carbopack C, Tenax GC and activated Charcoal (trade name $\mathrm{CNH}$ charcoal). Charcoal was found to be the best among the adsorbents to simultaneously collect gaseous methanol, ethanol, acetone and pentane because of its overall strong adsorbability and good recoveries as shown in Table II.

\section{Desorption and Recovery}

The following conclusions can be drawn from our experiment results:

1. The recoveries were obviously effected by the carrier gas flow rate, optimally at $2 \mathrm{~mL} \mathrm{~min}^{-1}$. 
Table I. Retention times of the components on Paropack Q columns $\left(\mathrm{T}_{\mathrm{c}}=145^{\circ} \mathrm{C}\right)$.

\begin{tabular}{|lc|}
\hline Analyte & Retention time (min) \\
\hline Methanol & 1.15 \\
Ethanol & 2.33 \\
Acetone & 3.78 \\
n-Pentane & 5.05 \\
\hline
\end{tabular}

Table II. Recoveries of analytes with different adsorbents.

\begin{tabular}{|c|c|c|c|c|}
\hline \multirow[t]{2}{*}{ Adsorbent } & \multicolumn{4}{|c|}{ Recovery (\%) } \\
\hline & Methanol & Ethanol & Acetone & Pentane \\
\hline Carbopack C & 0 & 0 & 0 & 0 \\
\hline Tenax GC & 0 & 0 & $<50$ & $<50$ \\
\hline Charcoal & 100 & 85 & 75 & $60-70$ \\
\hline
\end{tabular}

Table III. Concentration of volatile compounds in ambient air and human exhalation at different places and times.

\begin{tabular}{|llcccc|}
\hline \multirow{2}{*}{$\begin{array}{l}\text { Type of } \\
\text { sample }\end{array}$} & Date and Place & \multicolumn{4}{c|}{ Concentration (ng mL } \\
& & Methanol & Ethanol & Acetone & n-Pentane \\
\cline { 3 - 6 } & & 22 & 23 & 7 & - \\
\hline \multirow{2}{*}{ Ambient air } & May 17, chem. lab. & 7.6 & 5.1 & - & - \\
& May 17, corridor & 0.4 & 0.5 & 1 & 0.3 \\
& May 21, chem. lab. & 2.1 & 3.9 & 3 & 0.2 \\
& May 22, chem. lab. & 2.2 & 1.9 & 0.8 & 0.1 \\
Breath & May 23, in chem. lab. & 0.3 & 0.4 & 0.8 & 0.3 \\
& May 23, in corridor & 0.05 & 0.2 & 0.5 & 0.2 \\
& May 23, left lab. 1 h & 0.09 & 0.7 & 0.5 & 0.3 \\
& May 23, left lab 2.5 h & 0.1 & 0.3 & 0.4 & 0.3 \\
\hline
\end{tabular}

2. The recoveries of methanol, ethanol, acetone and pentane were $100 \%, 85 \%, 75 \%$, and $70 \%$ respectively, when the carrier gas flow-rate during the experiment was $25 \mathrm{~mL} \mathrm{~min}^{-1}$.

3. The reproducibility was $\pm 5 \%(\mathrm{n}=8)$ for $5200 \mathrm{ng}$ with a $500 \mu \mathrm{L}$ syringe and $\pm 5-15 \%(n=8)$ for $50-160 \mathrm{ng}$ with a $10 \mu \mathrm{L}$ syringe. The linear range was $0.05-5200 \mathrm{ng}$.

\section{Application}

The results presented in Table III and in Figure 3 were detected at some working and living places as well as in open areas. The amounts of methanol and ethanol in human breath were influenced by the environmental concentration and decreased a little after the people left the polluted air. The concentrations of acetone and pentane in exhalation respired by healthy persons, however, did not change greatly with their amounts in ambient air, as both of them were considered to be basic volatile metabolites in human breath. The change of their concentration in exhalation did not only relate to the influence of environment but also to the situation of the person's health.

\section{Conclusions}

The methodology developed in this paper using preenrichment on a small adsorbent column and thermal desorption onto the chromatographic column can provide rapid and sensitive analysis of low molecular weight volatile compounds such as methanol, ethanol, acetone and pentane in exhalation as metabolites or as markers to monitor the exposure to pollutants, in a relatively short time. The results obtained were as follows: with an analytical range of $0.05-5200 \mathrm{ng}$ (with linear regression coefficient $r>0.98$ ) the respective recoveries of methanol, ethanol, acetone and n-pentane were $100 \%$, $85 \%, 75 \%$ and $70 \%$. Our preliminary results illustrated that the methodology can serve as the basis for practical routine analyses. It is an easier and more sensitive assessment method as compared with those utilizing sample bags and mouth-cap.

\section{Acknowledgment}

This work was supported partly by a UNESCO course in analytical chemistry held in Charles University in Prague, Czech Republic and by the Chinese Academy of Science. The authors wish to thank Dr. Jech for his invaluable and helpful suggestions and encourragement, and Dr. Fattle for technical assistance. 

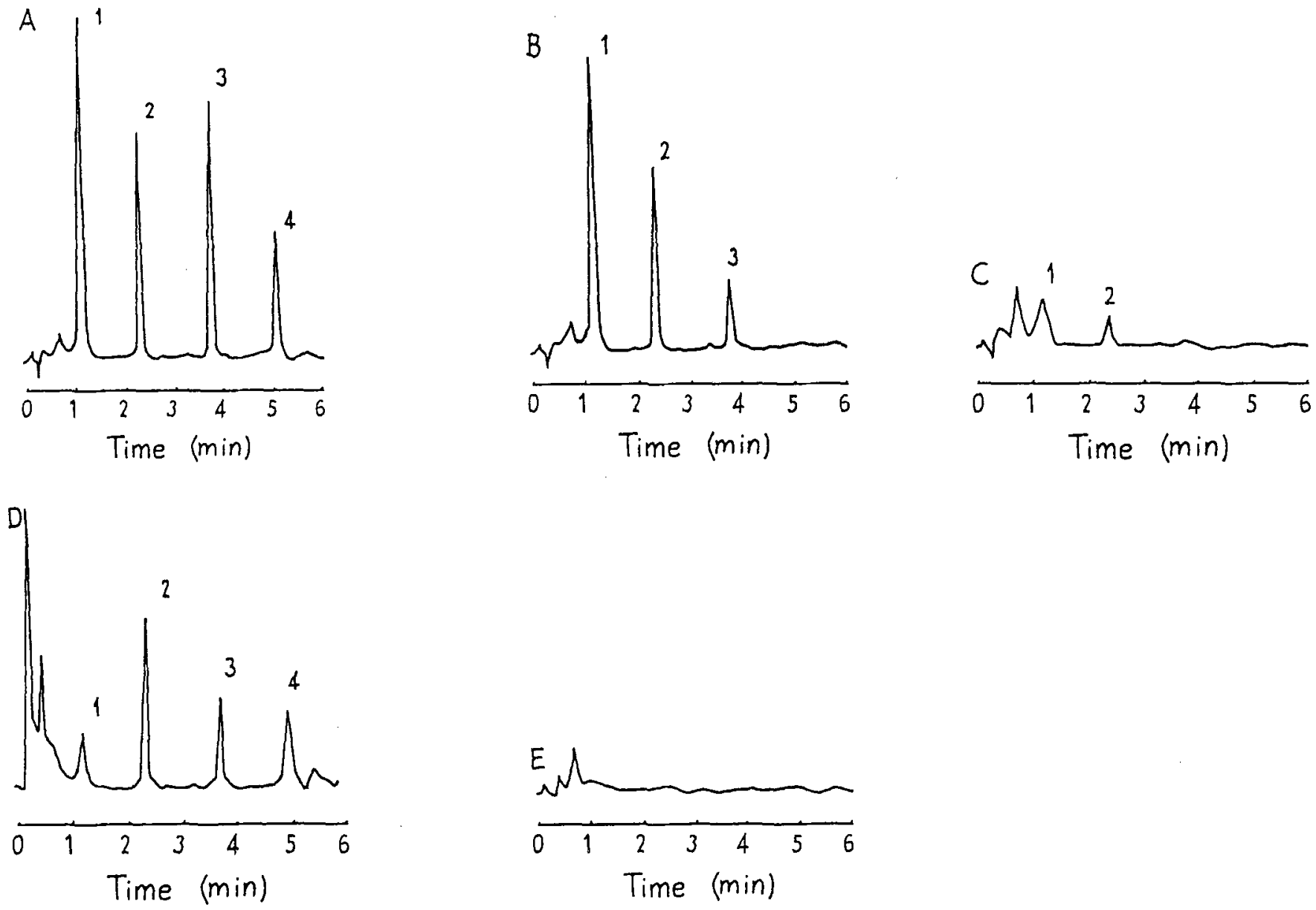

\section{Figure 3}

Chromatograms of various samples: $\mathbf{A}=$ standard mixture $; \mathbf{B}=$ air collected in a chemical laboratory $; \mathbf{C}=$ air collected in an open area $; \mathbf{D}=$ human breath collected in the chemical laboratory; $\mathbf{E}=$ blank. Sample volume: $250 \mathrm{~mL}$. Peaks: $1=$ methanol; $2=$ ethanol; $3=$ acetone; $4=\mathrm{n}$-pentane. [11] Reprinted from Talanta 2278 (in press, (1997)), Qin et al. A simple method for the trace determination of methanol, ethanol and pentane in human breath and in the ambient air by preconcentration on solid sorbents followed by gas chromatography, with kind permission of Elsevier Sciences, Sara Burgerhartstraat 25, 1055 KV Amsterdam, The Netherlands.

\section{References}

[1] R. Teranishi, T. R. Mon, A. B. Robinson, P. Cary, L. Pauling, Anal. Chem. 44, 18 (1972).

[2] H. L. Gearhart, D. P. Bose, C. A. Smith, R. D. Morrison, J. D. Welsh, T. K Smalley, Anal. Chem. 48, 393 (1976).

[3] G. Castello, T. C. Grebino, A. Giacnsa, F. Frascio, S. G. Sukkar, J. Chromatogr. B. 416, 119 (1987).

[4] J. Peinado, F.J. Lopez-Soriano, J. M. Argiles, J.Chromatogr. B 415, 372 (1987)

[5] A. Zlatkis, H. A. Lichtenstein, A. Tishbee, Chromatographia 6, 67 (1973).

[6] M. Phillips, J. Greenberg, J. Chromatogr. B. 422,235 (1987).

[7] H. Yang, Z. L. Cheng, Environmental Chemistry (Huanjing Huaxue) (China) 6, 39 \{1987).

[8] A. Fabbri, G. Crescentini, F. Mangani, A. R. Mastrogiacomo, F. Bruner, Chromatographia 23, 856 (1987).

[9] J. Namiesnik, Talanta 35, 567 (1988).

[10] K.-A. Person, S. Berg, Chromatographia 27, 55 (1989).

[11] T. Qin, X. B. Xu, T. Polak, V. Pacakova, K. Stulik, L. Tech, Talanta (1997), in press. 